Zaid Abdulazeez Muhammad BDS, MSc. (Asst. Lec.)

\section{Clinical and Histological Effects of N- acetyl Cysteine Intraperitoneal Injection on Primary Wound Healing in Rabbits.}

\author{
Department of Oral and Maxillofacial Surgery \\ College of Dentistry, University of Mosul
}

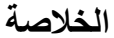

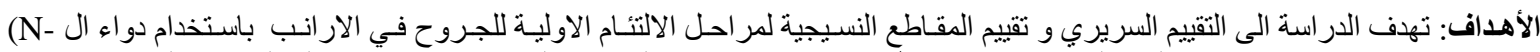
acetylcystine)

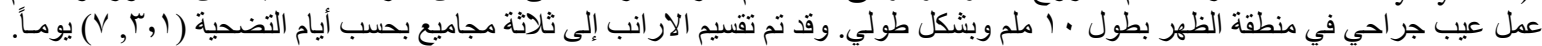

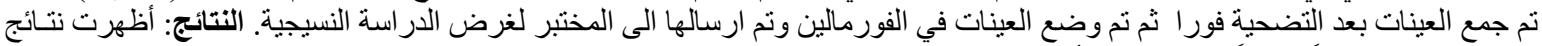

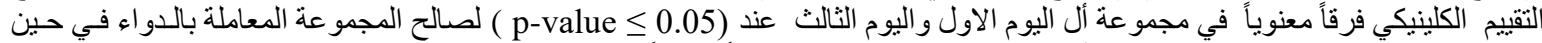

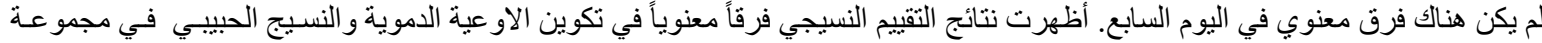

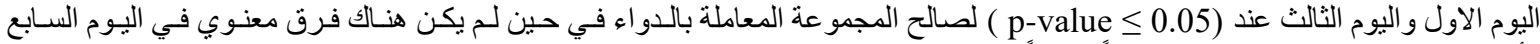

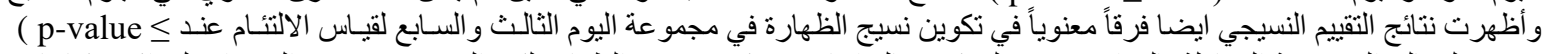

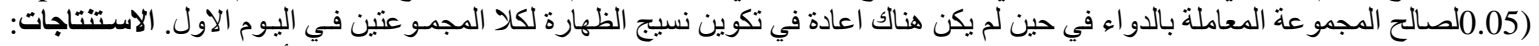

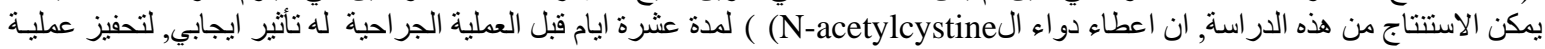

ABSTRACT

\begin{abstract}
Aims: This study aims to investigate the effect of ten days of intraperitoneal injection of $\mathrm{N}$-acetyl cysteine (NAC) on full thickness wound healing of the skin, using a rabbit model. Materials and Methods: Thirty male rabbits were used to conduct this study. A full - thickness linear incision, $(10 \mathrm{~mm})$ was induced on the back of each rabbit and divided into two groups. Group 1: no treatment (control group) and group 2 (NACtreated group) was injected intraperitoneally ten days before wound induction. Animals were randomly divided into three groups according to sacrificing date (1,3 and 7) days. The site of intervention was assessed clinically and histopathologically on the 1st, 3rd, and 7th day of the experimental procedure. Results: The clinical observation of tissue type revealed that there were significant differences in type of tissue at 1 and 3 days at pvalue $\leq 0.05$, and the wound healing was converted to granulation tissue without slough and necrotic tissue formation. There was no significant difference at 7 days compared to the control group. The histopathological finding showed that there were significant differences in angiogenesis and granulation tissue formation between the two groups at 1 and 3 days at $p$-value $\leq 0.05$, while there was no significant difference at 7 days. There was a significant difference of reepithelization at 3 and 7 days at $p$-value $\leq 0.05$. Conclusions: Ten days of intraperitoneally $\mathrm{N}$-acetyl cysteine injection before surgical procedures will significantly enhance the process of primary wound healing of rabbit skin on secondary wounds.
\end{abstract}

Keywords: N-acetyl cysteine, Intraperitoneal, Wound healing, Epithelialization.

Clinical and Histological Effects of $\mathrm{N}$-acetyl Cysteine Intraperitoneal Injection on Primary Wound Healing in Rabbits. Al-Rafidain Dent J. 2021; 21(2):165-176.

DOI: $10.33899 /$ rdenj.2021.129487.1087 (C2021, College of Dentistry, University of Mosul.

Received: 4/2/2021

Sent to Referees: 10/2/2021

Accepted for Publication: 11/4/2021

This is an open access article under the CC BY 4.0 license (http://creativecommons.org/licenses/by/4.0/). 


\section{INTRODUCTION}

Soft tissue injury is a worldwide clinical challenge that could occur secondary to surgical procedures, trauma (like an accident, war injuries), and pathological reasons ${ }^{(1,2)}$. Annually, millions of people around the world suffering from acute and chronic wounds which could be complicated by many factors ${ }^{(3,4)}$.

Wound healing is a biological natural process of the body for regenerating the tissue of dermis and epidermis of the skin ${ }^{(5)}$. This process consists of a highly programmed balanced activity of inflammation, vascular proliferation, formation of connective tissue, and migration of cells leading to restoration of tissue integrity (6).

Enhancing healing of the soft tissue defect is still a crucial and important subject in the surgical field ${ }^{(7,8,9)}$. The acceleration of the wound healing process could significantly reduce mortality and morbidity from complicated wounds ${ }^{(10) .}$

Many modalities have been utilized to stimulate wound healing. Medication with antioxidant activity has a remarkable effect to enhance wound healing. Current strategies point out using antioxidant drugs to decreases oxidative stress by eliminating reactive oxygen species (ROS) which has an harmful effect on the wound healing process ${ }^{(11,12)}$.

$\mathrm{N}$-acetyl cysteine is an inexpensive and safe drug with strong antioxidant properties ${ }^{(13)}$.It has a sulfhydryl molecule which is a precursor in the glutathione (GSH) formation inside the body .It was used as a mucolytic agent for many years and also commonly applied in the treatment of acetaminophen over dose to prevent liver toxicity ${ }^{(14)}$.It has been used as a combined therapy in the treatment of many diseases such as human immunodeficiency virus (HIV), diabetes, cystic fibrosis, Alzheimer's disease and in both nephropathy and pulmonary diseases ${ }^{(15,16)}$. These therapeutic properties are attributed to free radical scavenger ability of NAC ${ }^{(17)}$. Furthermore, NAC is potentially used for the management of oral diseases especially gum infection due to the antimicrobial activity that led to the destruction of biofilms of many relevant pathogens ${ }^{(18)}$.

Recently, some studies reported that NAC could have the ability to enhance healing of many types of wounds ${ }^{(19,20)}$. The wound healing effects of NAC are owned to its antioxidant action, supporting the system of nitric oxide and enhancing the proliferation of cell which are crucial in the process of wound healing ${ }^{(21)}$. NAC could be used systemically, orally, and topically to enhance the wound healing ${ }^{(22)}$. However, NAC has a strong bad taste when administrated orally and is associated with gastrointestinal disturbance ${ }^{(23)}$. Furthermore, the administration of the NAC intravenously could result in an anaphylactic reaction, ranging from rash, angioedema and pruritus to hypotension and bronchospasm ${ }^{(24)}$. The intraperitoneal injection of NAC could be a good alternative to overcome the side effects of both oral and intravenous administration of NAC. However, 
evidence-based research supporting the use of intraperitoneal injection of NAC to enhance tissue repair is scarce.

This paper aims to investigate the clinical and histopathological effects of intraperitoneal injection of NAC at a dose of $300 \mathrm{mg} / \mathrm{kg}$ for ten consecutive days before surgical procedure. The hypothesis is that ten days of intraperitoneal injections of NAC will enhance healing process without remarkable side effects.

\section{MATERIALS AND METHODS}

This study was conducted in the College of Dentistry, University of Mosul, Iraq and was approved by the scientific and ethical committee and the guidelines for the use and care of animals (UoM. Dent/A.21/20). Thirty, 6-8 months old local male rabbits were selected for this study weighing around $(1.5-2 \mathrm{Kg})$. All rabbits were housed under the same condition. Access to food and water was the same until 5 hours before injection with anesthesia.

Rabbits were randomly divided into two groups $(n=15)$; a control group without treatment and the treatment group where the rabbits were administrated with an intraperitoneal injection of NAC (ASIST 300 mg/3 ml Ampoule, Istanbul, Turkey) at a dose of $300 \mathrm{mg} / \mathrm{kg}$ body weight per day for ten days before the surgical procedure.

According to the sacrificing date, rabbits were randomly subdivided into three groups with each group of ten rabbits (five rabbits from the control group and five rabbits from the treated group):

G1: Rabbits were sacrificed after 1 days.

G2: Rabbits were sacrificed after 3 days.

G3: Rabbits were sacrificed after 7 days.

For achieving optimum general anesthesia, each rabbit was induced with a mixture of intramuscular dose of xylazine base (muscle relaxant and sedative) $(5 \mathrm{mg} / \mathrm{kg})$ in addition to ketamine hydrochloride (analgesic and anesthetic) $(50 \mathrm{mg} / \mathrm{kg})$ injected into the rabbit's thigh muscle ${ }^{(25)}$.

The back of each rabbit was clipped to remove the hair in the dorsal area and were covered with sterile surgical towel exposing the wound site only. The surgical site was disinfected by scrapping the area using a sterile gauze soaked with povidone-iodine solution $10 \%$ and the surgical procedure steps were performed under an aseptic technique. The wound area was traced using a pen marker on the skin (Figure $1)$.

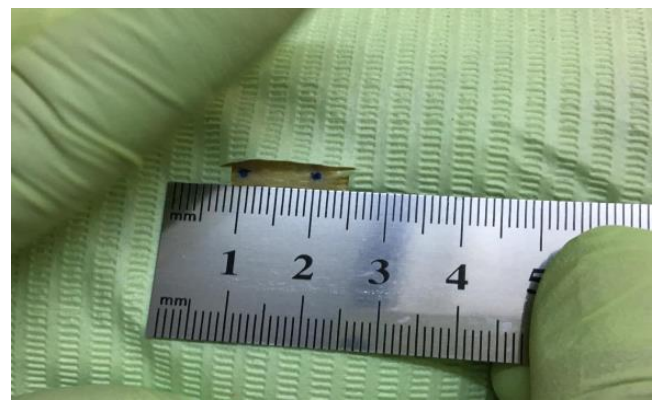

Figure. 1: The hair was clipped and the wound area was traced using a pen marker on the back of each rabbit.

A surgical blade No. 11, was used to make a full-thickness linear incision approximately 10 
$\mathrm{mm}$ and 3-4 $\mathrm{mm}$ in thickness on the back of each rabbit as shown in (Figure 2).

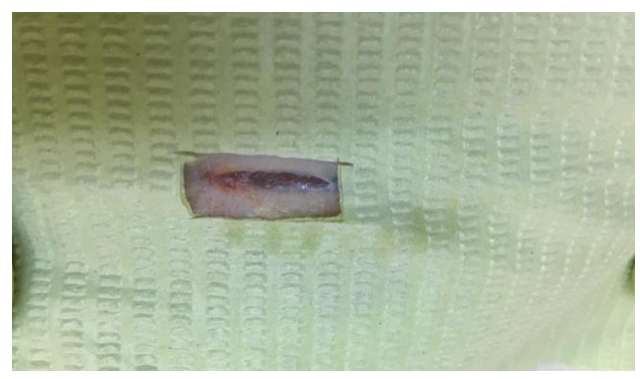

Figure. 2: A full-thickness longitudinal incision approximately $10 \mathrm{~mm}$ were made on the back of each rabbit

After the surgical procedure, the rabbits were placed in special separated cages and closely observed until full recovery and then were returned to their housing. At each sacrificing date of each group, the skin at the wound induction site was excised and preserved in $10 \%$ formalin and dehydrated in ascending levels of ethanol alcohol and processed with $x y-$ lene, then embedded with blocks of paraffin wax . The blocks were sliced serially by using the microtome, these slices about $4-5 \mu \mathrm{m}$ in thickness. The specimens were put on glass slides and processed with xylol, alcohol and stained by hematoxyline and eosin and sent for a histopathological examination ${ }^{(26)}$.

\section{Clinical observation of the type of tissue:}

This score is used to describe the type of tissue formed at the bed of the wound by using Ghada et al criteria with some modifications: (27)

4: Dead and necrotic tissue.

3: Slough tissue.
2: Formation of granulation tissue.

1: Formation of epithelial tissue.

0 : Wound is closed(full thickness of epithelium) .

The histopathological examination was made by two histopathologists to assess the following:

A) New blood vessels formation score: ${ }^{(28)}$

- Score 0:Absent of blood vessels.

-Score 1:Peripherally present blood vessels.

-Score 2:Centrally present blood vessels.

-Score 3:Centrally and peripherally present blood vessels.

B) Granulation tissue formation score: ${ }^{(28)}$

-Score1:Absent formation of granulation tissue.

-Score2:Scanty amount formation of granulation tissue.

-Score3:Moderate amount formation of granulation tissue.

-Score4:Profound amount formation of granulation tissue.

C) Reepthelialization process: ${ }^{(29)}$

Score 0: Reepithelialization at the wound edge only.

Score 1: Reepithelialization below the half of the wound.

Score 2: Reepithelialization above the half of the wound.

Score 3: Irregular full thickness of reepithelialization of the wound area.

Score 4: Normal full thickness of reepithelialization of the wound area.

\section{Statistical analysis}

Statistical analysis was made by using SPSS 19 computer software program (SPSS, Cary, North Carolina, USA). Data were presented as means and standard deviation (SD). The Mann - Whitney NPar Test was used to 
compare means between groups. Significant levels were set at $\mathrm{p} \leq 0.05$.

\section{RESULTS}

During the post-operative period, all animals had no clinical signs of infection. Furthermore, the histological examination confirmed the aseptic condition of wound healing process in both control and treated groups.

Clinical observation of the wounds at the first day revealed that the mean score of treated group with NAC \pm SD was $(3.8 \pm 0.44)$ and the granulation tissue started to form directly without formation of necrotic tissue in the wound induction area. In contrast to the control group, the clinical score for tissue type \pm SD were (2.6 \pm 0.54 ) in which necrotic and slough tissue were formed and there was a statistically significant difference between the two groups at $\mathrm{p}$-value $\leq$ 0.05 .

At the third day, the mean of clinical score for tissue type $\pm \mathrm{SD}$ in the treated group was $(2.0 \pm 0.0)$ and the wounds were converted to granulation tissue in the treated group without slough tissue. On the other side, the mean of clinical score of control group was $(2.8 \pm 0.44)$, the wound area contained both slough tissue and granulation tissue and there was statistically significant difference between two groups.

At the seventh day, the mean for clinical score for the treated group was $(1.2 \pm 0.4)$, in contrast to the control group was $(1.4 \pm 0.5)$ without a statistically significant difference between two groups and as shown in (Table 1).

Table 1: Clinical score for tissue type for both control and treated group

\begin{tabular}{cccc}
\hline Periods & Control group (Mean + SD) & Treated group (Mean + SD) & p-value \\
\hline Day 1 & $3.8 \pm 0.44$ & $2.6 \pm 0.54$ & $0.016^{*}$ \\
Day 3 & $2.8 \pm 0.44$ & $2.0 \pm 0.0$ & $0.032^{*}$ \\
Day 7 & $1.4 \pm 0.5$ & $1.2 \pm 0.4$ & 0.69 \\
\hline
\end{tabular}

Data were described as (mean $\pm \mathrm{SD})$. Significance $(*): p$-value $\leq 0.05$.

However, in the treated group, the wound closure was faster than the control group. The histological examinations supported the clinical findings results. The histological examination and the scoring of the specimen were performed blindly by the specialist. The evaluation of angiogenesis, inflammation, fibrosis and epithelization degrees was done using scoring systems.
On the first day after skin incision, the histological observation of control group showed a wide gap in the wound defect area with peripherally present blood vessels. The mean score \pm SD for angiogenesis was $(1 \pm 0.0)$ and there was absence of granulation tissue with no epithelization (Figure 3). 


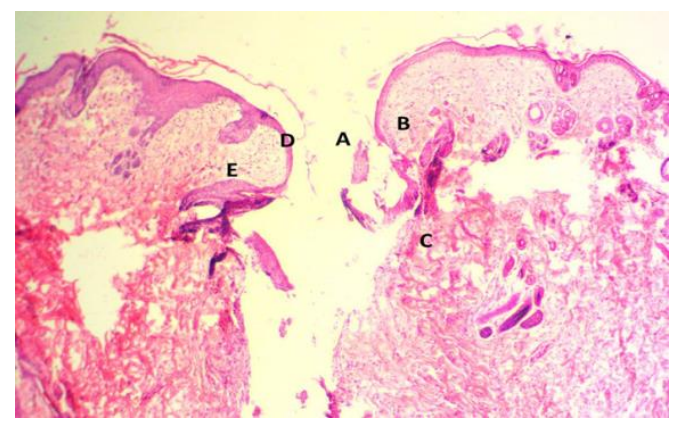

Figure 3: photomicrograph of skin of control group (day 1) shows the site of wound with wide gap (A) representing by peripherally present blood vessels (angiogenesis) (B), absence of granulation tissue formation (C), and re-epithelialization at the wound edge (score 0$)(\mathrm{D})$ and presence of of inflammatory cells infiltrate (E). H\&E stain, 40X.

In the treated group, the mean score $\pm \mathrm{SD}$ tissue in the wound site area with a mean score for angiogenesis was $(2 \pm 0.70)$ and was signifi- for granulation tissue formation was cantly higher than the control group. Further- $(1.8 \pm 0.447)$ and as shown in (Figure 4,Table more, there was a scanty amount of granulation 2).

Table 2 : Score for new blood vessels formation

\begin{tabular}{cccc}
\hline Periods & $\begin{array}{c}\text { (Mean }+ \text { SD) Control } \\
\text { group }\end{array}$ & $\begin{array}{c}\text { Treated group } \\
\text { Mean }+ \text { SD }\end{array}$ & p -value \\
\hline Day 1 & $1 \pm 0.0$ & $2 \pm 0.70$ & $0.032^{*}$ \\
Day 3 & $1.2 \pm 0.4$ & $2.8+0.4$ & $0.008^{*}$ \\
Day 7 & $2.60 \pm 0.54$ & $2.90 \pm 0.3$ & 0.31 \\
\hline
\end{tabular}

Data were describe as (mean $\pm \mathrm{SD})$. Significance $(*)$ :p-value $\leq 0.05$.

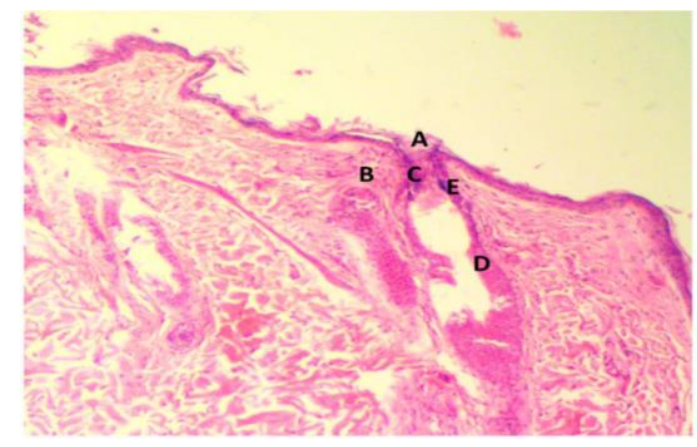

Figure. 4: photomicrograph of skin of treated group (day 1) shows the site of wound area (A) representing by peripherally present blood vessels (angiogenesis) (B), scanty amount of granulation) (C), reepithelialization at the wound edge (score 0) (D) and presence of inflammatory cells (E). H\&E stain, 40X. 
At the third day after skin incision, the mean score for angiogenesis in the control group was (1.2 \pm 0.4$)$ compared to treated group in which the mean score for angiogenesis was $(2.8+0.4)$ as shown in (Table 2). There was a statistically significant difference between the two groups. Furthermore, the mean score for both granulation tissue formation and reepithelization for the control group were $(1.8 \pm 0.44)$ and $(0.6 \pm 0.54)$ respectively. In the treated, the means were $(3 \pm 0.83)$ and $(1.8 \pm 0.44)$ for both granulation tissue formation and reepithelization respectively and there was a statistically significant difference between the two groups. The rabbits with NAC group showed more rapid epithelialization and granulation tissue formation when compared to the control group (Figures 5, 6), (Tables 3, 4).

Table 3: Score for granulation tissue formation

\begin{tabular}{cccc}
\hline Periods & (Mean + SD) Control group & (Mean + SD)Treated group & p-value \\
\hline Day 1 & $1 \pm 0.0$ & $1.8 \pm 0.447$ & $0.032 *$ \\
Day 3 & $1.8 \pm 0.44$ & $3 \pm 0.83$ & $0.032 *$ \\
Day 7 & $3.4 \pm 0.54$ & $3.6 \pm 0.54$ & 0.69 \\
\hline
\end{tabular}

Data were describe as (mean \pm SD), Significance (*):p-value $\leq 0.05$.

Table 4: Score for Re-epithelialization process

\begin{tabular}{cccc}
\hline Periods & $($ Mean + SD)Control group & Treated group Mean + SD & p -value \\
\hline Day 1 & 0 & 0 & 1 \\
Day 3 & $0.6 \pm 0.54$ & $1.8 \pm 0.44$ & $0.016^{*}$ \\
Day 7 & $1.8 \pm 0.44$ & $2.8 \pm 0.44$ & $0.032^{*}$ \\
\hline
\end{tabular}

Data were describe as (mean \pm SD). ,Significance $(*)$ :p-value $\leq 0.05$.

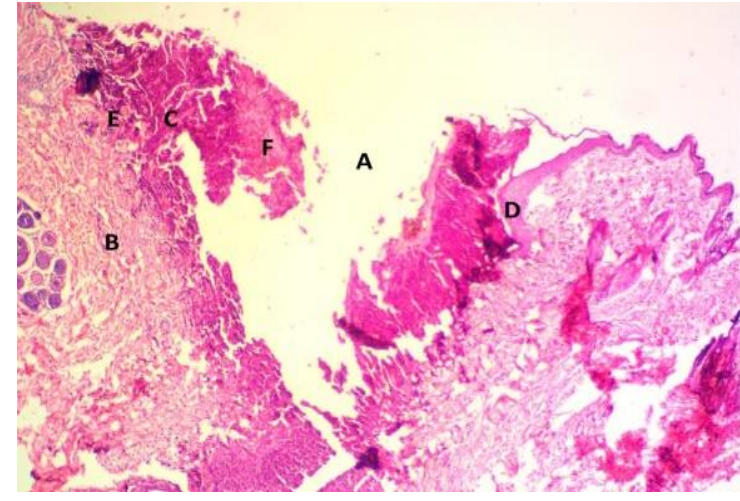

Figure. 5: photomicrograph of skin of control group (day 3 ) shows the site of wound with wide gap (A) representing by peripherally present blood vessels (angiogenesis) (B), granulation tissue $(\mathrm{C})$, re-epithelialization at the wound edge (score 0) (D), present of inflammatory cells (E) and thickening of keratin layer $(\mathrm{F})$. H\&E stain, $40 \mathrm{X}$.

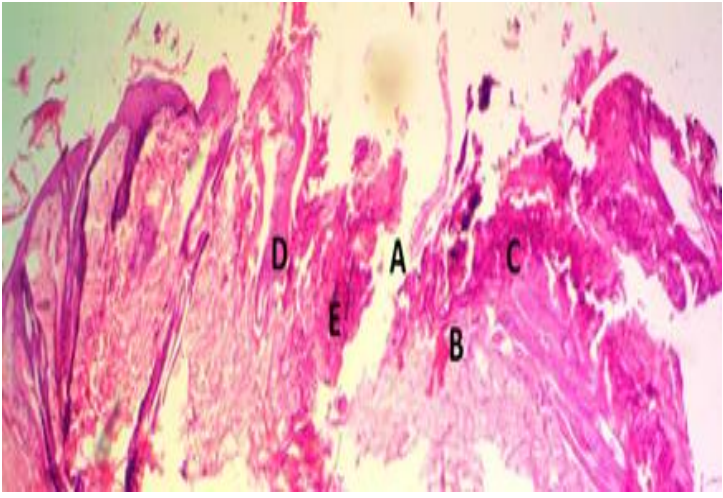

Figure. 6: photomicrograph of skin of treated group (day 3) shows the site of wound with an occluded gap (A) representing by centrally and peripherally present blood vessels (angiogenesis) (B), profound amount of granulation $(\mathrm{C})$, irregular full thickness of reepithelialization at the wound edge (D) and presence of inflammatory cells (E). H\&E stain, 40X. 
At the seventh day, the mean score for both angiogenesis and granulation tissue formation in the control group was $(2.60 \pm 0.54)$ and (3.4 \pm 0.54$)$ respectively. The treated group, the means were $(2.90 \pm 0.3)$ and (3.6 \pm 0.54$)$ for angiogenesis and granulation tissue formation respectively. The results showed a statistically

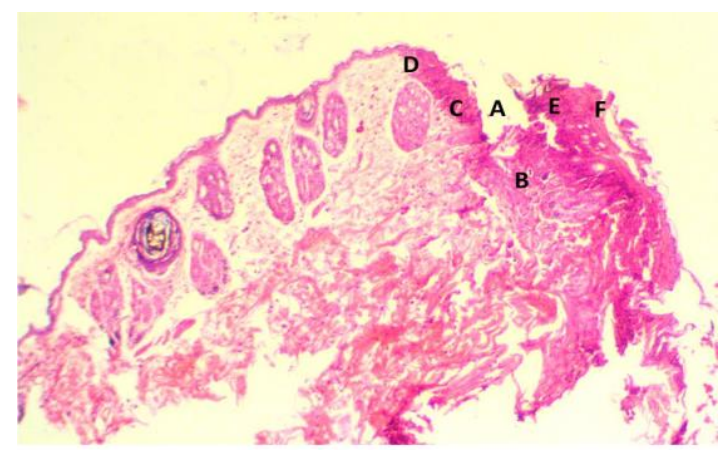

Figure. 7: photomicrograph of skin of control group (day 7) shows the site of wound (A) representing by centrally and peripherally present blood vessels (angiogenesis) (B), moderate amount of granulation $(\mathrm{C})$, reepithelialization bellow the half of the wound edge (D), present of inflammatory cells $(\mathrm{E})$ and thickening of keratin layer (F). H\&E stain, 40X.

\section{DISCUSSION}

In this study, the clinical and histopathological results supported the hypothesis, indicating that ten consecutive days after intraperitoneal injection of $\mathrm{N}$-acetyl cysteine appears to significantly accelerate wound healing on experimentally induced wound defects in skin tissue of a rabbit model without significant side effects.

NAC has a powerful antioxidant effect and has the ability to enhance Glutathione (GSH) syn- significant difference between the two groups. The mean scores for both control group and treated group of reepithelization were $(1.8 \pm 0.44)$ and $(2.8 \pm 0.44)$ respectively. The rate of re-epithelization was significantly higher in treated group than in the control group and as shown in (Figure 7,8), (Table 2, 4).

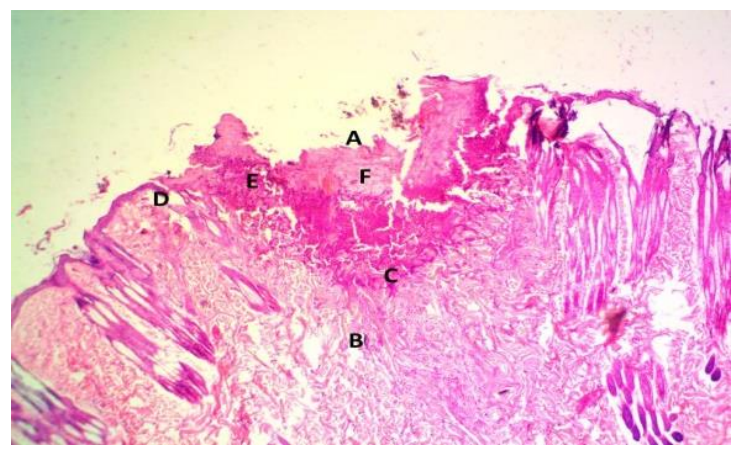

Figure. 8: photomicrograph of skin of treated group (day 7) shows the site of wound (A) representing by centrally and peripherally present blood vessels (angiogenesis)(B), moderate amount of granulation (C), irregular full thickness of reepithelialization above the half of the wound (D) and present of inflammatory cells (E) and thickening of keratin layer (F).

H\&E stain, 40X.

thesis and prevents oxidative stress and inflammation and accelerate wound healing process ${ }^{(30)}$. In the process of wound healing, reactive oxygen species (ROS) are produced by many inflammatory cells, including macrophages, neutrophils, , fibroblasts and endothelial cells . Formation of ROS in response to tissue injury on wounds has a harmful effect on the membrane of cells, protein lipids and DNA leading to constraining the wound healing pro- 
cess . Glutathione is an important antioxidant and act as a scavenger removing ROS from the wound area which causes tissue destruction ${ }^{(31)}$. The clinical examination of the wound area in the treated group revealed a less degree of tissue destruction with no dead or necrotic tissue in the first days after wound induction in contrast to control group in which the necrotic and slough tissue were observed clinically during the wound healing process . This could be attributed to the antioxidant effect of NAC.This is supported by an experiment conducted by Deniz et $a l$, in which they used comb-burn rat models to compare between the degree of necrosis in burn wound between a treated group in which rats received NAC and no treatment group. They found that there was a significant difference between the two groups in the degree of necrosis and concluded that NAC has a powerful antioxidant effect since it has the ability to protect and save the zone of stasis and decrease the degree of tissue destruction and necrosis ${ }^{(32)}$. Furthermore, the potential antibacterial effect of NAC could decrease the incidence of infection and prevent formation of dead and necrotic tissue. Yamada et al. found in their study that NAC has the ability to inhibit a variety of wound pathogens such as Streptococci and Staphylococci and prevent wound infection which plays a significant effect to enhance regeneration of tissue ${ }^{(33)}$. Another study conducted by Sahib etal in which they found that the administration of anti-oxidants, vitamin $\mathrm{E}$ and NAC in burn patients, have shown sig- nificant effects in the management of burn patients by decreasing the infection incidence and reducing healing time ${ }^{(34)}$.

Angiogenesis has an important role in the wound healing process ${ }^{(35)}$.In this study ,the histopathological examination of wound area of treated group revealed that NAC appeared to enhance angiogenesis and perfusion of blood vessels to the healing site with a significant difference in angiogenesis between the two groups at first and third day period.

This agreed with a study conducted by Aktunç et al which showed that NAC has the ability to enhance tissue repair by stimulating angiogenesis during the process of wound healing and removing free radicals by direct scavenging action of NAC ${ }^{(36)}$.

Furthermore, the histopathological examination showed that the healing process was faster in the treated group when compared to the control group with a statistically significant difference in epithelialization of NAC group compared to the control group in the third- and seven-day period.

Abdulla et al. concluded in their study that better wound healing ratios and epithelialization ratios were obtained in the NAC group than in the control group, and the mean fibrosis score was significantly higher in the NAC group than in the control group ${ }^{(37)}$.

This study was limited to rabbits. However, further clinical studies should be conducted on humans to examine the benefits and conven- 
ience of intraperitoneal administration of NAC on wound healing in humans .

\section{CONCLUSIONS}

Ten days of pre-operative intraperitoneal injections of NAC is a safe, relatively convenient and inexpensive method for reducing wound healing time and without significant side effects.

\section{REFERENCES}

1. Manus Mc J. Principle of Skin and Wound Care. The Palliative Approach. End of Life Care. 2007; 1(1): 8-19.

2. Mann A, Ajiboso O, Ajeigbe S, Gbate M and Isaiah S. Evaluation of Wound Healing Activity of Ethanol Extract of Terminalia Avicennioides Root Bark on Two Models in Rats. Int. Med. Atom. Plants. 2011; 1(2): 95100.

3. Sen CK, Gordillo GM, Roy S, Kirsner R, Lambert L, Hunt TK, Gottrup F, Gurtner GC, Longaker MT. Human skin wounds: a major and snowballing threat to public health and the economy. Wound Repair Regen. 2009;17(6):763-71.

4. 4)Meier, K., Nanney, L., Emerging new drugs for wound repair. Expert Opi ion in Emerging Drugs.2006; 11(1): 23-37.

5. Richardson R, Slanchev K, Kraus C, Knyphausen P, Eming S, Hammerschmidt M. Adult zebrafish as a model system for cutaneous wound-healing research. $J$ Invest Dermatol.2013; 133(6): 1655-1665.
6. Lindley LE, Stojadinovic O, Pastar I, Tomic-Canic M. Biology and Biomarkers for Wound Healing. Plast Reconstr Surg. 2016;138(3 Suppl):18S-28S.

7. Priya KS, Arumugam G, Rathinam B, Wells A, Babu M. Local injection of insulin-zinc stimulates DNA synthesis in skin donor site wound. Wound Repair Regen. 2007;15: 258-265.

8. Priya KS, Arumugam G, Rathinam B, Wells A, Babu M. Local injection of insulin-zinc stimulates DNA synthesis in skin donor site wound. Wound Repair Regen. 2007;15: 258-265.

9. Kairuz E, Upton Z, Dawson RA, Malda J. Hyperbaric oxygen stimulates epidermal reconstruction in skin equivalents. Wound Repair Regen. 2007; 15:266-274.

10. Darwin, E., Tomic-Canic, M. Healing Chronic Wounds: Current Challenges and Potential Solutions. Curr Derm Rep.2018;7(4) :296-302.

11.Sun SY. N-acetylcysteine reactive oxygen species and beyond. Cancer Biol Ther. 2010 ; 9(2): 109-110.

12.Pompella A, Visvikis A, Paolicchi A, De Tata V, Casini AF. The changing faces of glutathione, a cellular protagonist. BiochemPharmacol. 2003;66(8):1499 -1503 .

13. Youssef G, Meguid Ali A, Alaa N, Makin B, Waly M, AbouSetta A. N-acetylcysteine in an ovulatory women: the impact 
of postcoital test. Middle East Fertil Soc J. 2006;11(2):109-112.

14.Flannagan RJ, and Meredith TJ. Use of Nacetylcysteine in clinical toxicology. Am J Med. 1991;91(3C):131S-139S.

15.Dodd S, Dean O, Copolov DL, Malhi GS, Berk M. N-acetylcysteine for antioxidant therapy: Pharmacology and clinical utility. Expert Opin Biol Ther 2008;8(12):1955-62

16. Manus Mc J. Principle of Skin and Wound Care. The Palliative Approach. End of Life Care . 2007 ; 1(1): 8-19.

17. Millea PJ. N-acetylcysteine: Multiple clinical applications. Am Fam Physician. 2009;80(3):265-9.

18. M. Yamada, K. Ishihara, T. Ogawa, and K. Sakurai, "The inhibition of infection by wound pathogens on scaffold in tissue-forming process using N-acetyl cysteine," Biomaterials, 2011; 32( 33) : 8474-8485.

19.Deniz, M.; Borman, H.; Seyhan, T.; Haberal, M. An effective antioxidant drug on prevention of the necrosis of zone of stasis: NAcetylcysteine. Burns 2013, 39, 320-325.

20.Demir EO, Cakmak GK, Bakkal H, Turkcu UO, Kandemir N, Demir AS, et al. N-acetylcysteine improves anastomotic wound healing after radiotherapy in rats. $J$ Invest Surg. 2011;24(4):151-158.

21.Ozkaya H, Bahat G, Tufan A, Dogan H, Bilicen Z, Karan MA. Successful treatment of non-healing pressure ulcers with topical n-acetyl cysteine. $J$ Wound Care. 2015;24(12):606, 608-11.

22. Tsai M-L, Huang H-P, Hsu J-D, Lai Y-R, Hsiao Y-P, Lu F-J, Chang H-R. Topical NAcetylcysteine Accelerates Wound Healing in Vitro and in Vivo via the PKC/Stat3 Pathway. Int J Molecular Scie. 2014; 15(5):7563-7578.

23. Atkuri KR, Mantovani JJ, Herzenberg LA, Herzenberg LA. N-Acetylcysteine--a safe antidote for cysteine/glutathione deficiency. Curr Opin Pharmacol. 2007 Aug;7(4):3559.

24. Pakravan N, Waring WS, Sharma S, Ludlam C, Megson I, Bateman DN. Risk factors and mechanisms of anaphylactoid reactions to acetylcysteine in acetaminophen overdose. Clin Toxicol (Phila). 2008;46(8):697702.

25.Abramov Y, Hirsch E, Ilievski V, Goldberg RP, Botros SM, Sand PK. Transforming growth factor $\beta 1$ gene expression during vaginal vs cutaneous surgical wound expression during vaginal vs cutaneous surgical wound healing in the rabbit. Int Urogynecol J. 2013;24(4):671-5.

26. Tangella K. and Marjanovic M. Tissue Pathology: A Clinical Perspective. Popescu. New Technical Histopathology Part II: Review of Methods. 2010. P: 58-79.

27.Taqa GA., Mustafa E A., Al-Haliem SM. Evaluation of Anti-Bacterial and Efficacy of plant extract (Urtica urens) on Skin Wound 
Healing in Rabbit. Int J Enhanc Research

Science Techno and Engine. 2014;3 (1) : 64-

70.

28.Sultana J, Molla M, Kamal M, Shahidullah M,

Bashar M. Histological differences in wound healing in Maxillofacial region in patients with or without risk factors. Bangladesh J Pathology. 2009;24(1):3-8

29.Lopez-Jornet P, Alonso FC and MezGarci AF. Evaluation Of Biochemical The Two Cyanoacrylates: An Experimental Study in Rats. $J$ Biomater Applic.(2009);24: 197-207.

30.Benrahmoune $\mathrm{M}$, Therond $\mathrm{P}$, and Abedinzadeh. The reaction of superoxide radical with $\mathrm{N}$ acetylcysteine. Free RadicBiol Med 2000;29:775-82.

31.Dean O, Giorlando F, Berk M. $\mathrm{N}$-acetylcysteine in psychiatry: Current therapeutic evidence and potential mechanisms of action. $J$ Psychiatry Neurosci 2011;36(2):78-86.

32.Deniz M, Borman H, Seyhan T, Haberal M. An effective antioxidant drug on prevention of the necrosis of zone of stasis: N-acetylcysteine. Burns. 2013;39(2):320-5.
33. Yamada M, Ishihara K, Ogawa T, Sakurai $\mathrm{K}$. The inhibition of infection by wound pathogens on scaffold in tissue-forming process using $\mathrm{N}$-acetyl cysteine. Biomaterials. 2011 Nov;32(33):8474-8485.

34. Sahib AS, Al-Jawad FH, Alkaisy AA. Effect of antioxidants on the incidence of wound infection in burn patients. Ann Burns Fire Disasters. 2010;23(4):199-205.

35. Falanga V. Wound healing and its impairment in the diabetic foot. Lancet. 2005;366(9498):1736-1743.

36. Aktunc E, Ozacmak VH, Ozacmak HS, Barut F, Buyukates M, Kandemir O, Demircan N. N-acetyl cysteine promotes angiogenesis and clearance of free oxygen radicals, thus improving wound healing in an alloxan-induced diabetic mouse model of incisional wound. Clin Exp Dermatol. 2010;35(8):902-9.

37. Oguz A, Uslukaya O, Alabalık U, Turkoglu A, Kapan M, Bozdag Z. Topical $\mathrm{N}$-acetylcysteine improves wound healing comparable to dexpanthenol: an experimental study. Int Surg. 2015;100(4):656661. 